\title{
Article \\ Risk of Re-Rupture, Vasospasm, or Re-Stroke after Clipping or Coiling of Ruptured Intracranial Aneurysms: Long-Term Follow-Up with a Propensity Score-Matched, Population-Based Cohort Study
}

\author{
Jiaqiang Zhang ${ }^{1,+}$, Yang-Lan Lo ${ }^{2,+}$, Ming-Chang $\mathrm{Li}^{3}$, Ying-Hui Yu ${ }^{3}$ and Szu-Yuan Wu $4,5,6,7,8,9, *(\mathbb{D}$ \\ 1 Department of Anesthesiology and Perioperative Medicine, People's Hospital of Zhengzhou University, \\ Henan Provincial People's Hospital, Zhengzhou 450052, China; jiaqiang197628@163.com \\ 2 Department of Neurosurgery, Lo-Hsu Medical Foundation, Lotung Poh-Ai Hospital, Yilan 26546, Taiwan; \\ lyl3481@gmail.com \\ 3 Department of Colorectal Surgery, Lo-Hsu Medical Foundation, Lotung Poh-Ai Hospital, Yilan 26546, Taiwan; \\ C059019@mail.pohai.org.tw (M.-C.L.); c843024@mail.pohai.org.tw (Y.-H.Y.) \\ 4 Department of Food Nutrition and Health Biotechnology, College of Medical and Health Science, \\ Asia University, Taichung 41354, Taiwan \\ 5 Big Data Center, Lo-Hsu Medical Foundation, Lotung Poh-Ai Hospital, Yilan 26546, Taiwan \\ 6 Division of Radiation Oncology, Lo-Hsu Medical Foundation, Lotung Poh-Ai Hospital, Yilan 26546, Taiwan \\ 7 Department of Healthcare Administration, College of Medical and Health Science, Asia University, \\ Taichung 41354, Taiwan \\ check for \\ updates \\ Citation: Zhang, J.; Lo, Y.-L.; Li, \\ M.-C.; Yu, Y.-H.; Wu, S.-Y. Risk of \\ Re-Rupture, Vasospasm, or Re-Stroke \\ 8 Graduate Institute of Business Administration, Fu Jen Catholic University, Taipei 242062, Taiwan \\ 9 Centers for Regional Anesthesia and Pain Medicine, Wan Fang Hospital, Taipei Medical University, \\ Taipei 11696, Taiwan \\ * Correspondence: szuyuanwu5399@gmail.com \\ + These authors have contributed equally to this study (joint primary authors).
} after Clipping or Coiling of Ruptured Intracranial Aneurysms: Long-Term Follow-Up with a Propensity Score-Matched, Population-Based Cohort Study. J. Pers. Med. 2021, 11, 1209. https://doi.org/10.3390/ jpm11111209

Academic Editor: Won Hyuk Chang

Received: 26 September 2021

Accepted: 12 November 2021

Published: 16 November 2021

Publisher's Note: MDPI stays neutral with regard to jurisdictional claims in published maps and institutional affiliations.

Copyright: (c) 2021 by the authors. Licensee MDPI, Basel, Switzerland. This article is an open access article distributed under the terms and conditions of the Creative Commons Attribution (CC BY) license (https:/ / creativecommons.org/licenses/by/ $4.0 /)$.
Abstract: Scarce evidence is available in Asia for estimating the long-term risk and prognostic factors of major complications such as re-rupture, vasospasm, or re-stroke for patients with aneurysmal subarachnoid hemorrhage (SAH) undergoing endovascular coil embolization or surgical clipping. This is the first head-to-head propensity score-matched study in an Asian population to demonstrate that endovascular coil embolization for aneurysmal SAH treatment is riskier than surgical clipping in terms of re-rupture, vasospasm, or re-stroke. In addition, the independent poor prognostic factors of vasospasm or re-stroke were endovascular coil embolization, male sex, older age ( $\geq 65$ years; the risk of vasospasm increases with age), hypertension, congestive heart failure, diabetes, previous transient ischemic attack, or stroke in aneurysmal SAH treatment. Background: To estimate the long-term complications and prognostic factors of endovascular coil embolization or surgical clipping for patients with ruptured aneurysmal subarachnoid hemorrhage (SAH). Methods: We selected patients diagnosed with aneurysmal SAH between 1 January 2011 and 31 December 2017. Propensity score matching was performed, and Cox proportional hazards model curves were used to analyze the risk of re-rupture, vasospasm, and re-stroke in patients undergoing the different treatments. Findings: Multivariate Cox regression analysis revealed that the adjusted hazard ratio (aHR) of rerupture for endovascular coil embolization compared with surgical clipping was 1.36 (95\% confidence interval [CI]: 1.17-1.57; $p<0.0001)$. The aHRs of the secondary endpoints of vasospasm and re-stroke (delayed cerebral ischemia) for endovascular coil embolization compared with surgical clipping were $1.14(1.02-1.27 ; p=0.0214)$ and 2.04 (1.83-2.29; $p<0.0001)$, respectively. The independent poor prognostic factors for vasospasm and re-stroke were endovascular coil embolization, male sex, older age ( $\geq 65$ years; risk increases with age), hypertension, congestive heart failure, diabetes, and previous transient ischemic attack or stroke. Interpretation: Endovascular coil embolization for aneurysmal SAH carries a higher risk than surgical clipping of both short- and long-term complications including re-rupture, vasospasm, and re-stroke. 
Keywords: endovascular coil embolization; surgical clipping; aneurysmal subarachnoid hemorrhage; prognostic factors; complications

\section{Introduction}

Aneurysmal subarachnoid hemorrhage (SAH) is a life-threatening event. The primary aim of aneurysmal SAH management is the prevention of re-rupture (re-bleeding) by early repair with surgical clipping or endovascular coiling [1-3]. Additional measures are taken to reduce the risk of neurologic and systemic complications, particularly vasospasm and delayed cerebral ischemia (re-stroke) [4]. After aneurysmal SAH, the patient is at substantial risk of early re-rupture $(4 \%-14 \%$ in the first $24 \mathrm{~h}$, with maximal risk in the first 2-12 h) [2,5-8]. Re-rupture is associated with high mortality [2,5-8]. Aneurysm repair with surgical clipping or endovascular coiling is the only effective treatment to prevent re-rupture [2], but some risk of re-rupture remains even after repair [2,5-12].

Vasospasm and re-stroke are common delayed medical and neurologic complications after aneurysmal SAH repair and substantially increase morbidity and mortality [13-16]. Several modern neuromonitoring techniques have been developed since $2004[17,18]$. The changes in electrocorticogram, regional cerebral blood flow, and tissue partial pressure of oxygen that occur locally before, during and after the development of delayed cerebral infarction can be recorded by subdural optoelectrodes and intraparenchymal oxygen sensors [18]. Using these technologies and longitudinal neuroimaging, it was shown that the actual delayed cerebral ischemia is a consequence of spreading depolarizations that trigger a severe vasospasm in the microcirculation, which travels together with the neuronal depolarization wave in the gray matter and leads to the delayed infarctions [17]. In these neurovascular events, angiographic (proximal) vasospasm is merely a modifying factor that additionally adversely affects the actual pathophysiological processes in the neurovascular unit. However, the crucial pathophysiological problem is not proximal but distal, and not slow but highly dynamic. Many studies have assessed the risk and prognostic factors of vasospasm or re-stroke in the early phase; however, no long-term follow-up data are available to assess the long-term risk of vasospasm and re-stroke in patients with aneurysmal SAH following treatment with clipping or coiling.

Few studies have described long-term complications such as re-rupture, vasospasm, or re-stroke after standard aneurysmal SAH treatment. No clear head-to-head comparative data exist regarding complications between the two treatment techniques. Therefore, we performed a propensity score-matched study to reduce the selection bias of surgical clipping or endovascular coiling for patients with aneurysmal SAH and to compare the long-term risk of complications (re-rupture, vasospasm, or re-stroke) between the two treatments.

\section{Patients and Methods}

We conducted a population-based cohort study using the Taiwan National Health Insurance (NHI) Research Database (NHIRD). The NHIRD includes all medical claims data on disease diagnoses, procedures, drug prescriptions, demographics, and enrollment profiles of all beneficiaries [19]. We selected patients diagnosed with aneurysmal SAH between 1 January 2011 and 31 December 2017. The follow-up period was from the index date (defined as the date on which clipping or coiling was performed) to 31 December 2018. After adjustment for confounders, a Cox proportional hazards model was established to model the time from the index date to events (re-rupture, vasospasm, or re-stroke) in these patients. Our protocols were reviewed and approved by the Institutional Review Board of Tzu-Chi Medical Foundation (IRB109-015-B). The NHIRD contains detailed treatment-related information regarding the surgical procedures, in-hospital death, surgical clipping, and endovascular coil embolization [20-28]. The diagnosis of aneurysmal SAH was confirmed radiologically, and surgical clipping or endovascular coil embolization was 
performed as treatment. The inclusion criteria were patients $\geq 20$ years of age with first aneurysmal SAH diagnosis and early aneurysm repair (within 24-72 h) in patients with good-grade aneurysmal SAH (Hunt and Hess grades I-III). We excluded patients with a history of aneurysmal SAH before the index date, those who did not receive surgical clipping or endovascular coil embolization as treatment, and those who received it $>72 \mathrm{~h}$ after diagnosis [2]. Sequential intervention, such as surgical clipping for the recurrence of coiled aneurysms, was allowed in the current study because endovascular coil embolization was performed as the first treatment. However, we excluded patients receiving a combination of endovascular and surgical techniques in the same hospitalization because we aimed to compare the individual treatments for risk of complications. Accordingly, we divided the patients into two groups: those receiving endovascular coil embolization (group 1) and those receiving surgical clipping (group 1). Comorbidities were scored using the Charlson comorbidity index (CCI) $[29,30]$. Diabetes, congestive heart failure, hypertension, renal diseases, stroke, and transient ischemic attack (TIA) were not included in CCI scores to prevent duplicate weighting calculations for risk of postoperative complications. Only comorbidities observed $\geq 6$ months before the index date were included. Comorbid conditions were identified and included according to the diagnostic codes of the International Classification of Diseases, Ninth Revision, Clinical Modification (ICD-9-CM) for the first admission or more than two repeated main diagnosis codes during visits to the outpatient department.

To reduce the effects of potential confounding factors when comparing the risk of complications, propensity score matching (PSM) was performed using a multivariate logistic regression model with the treatment group as the dependent variable and potential confounders as the covariates. Logistic regressions were used for PSM, with the patients receiving endovascular coil embolization as the reference group. Interpretation and the Cox proportional hazards model were dependent on the proportional hazards assumption. Thus, our model assumptions were proportional to the hazards of the different treatments and case-mix variables based on the study by Grambsch [31], who proposed a practical test and an associated graph for examining the critical assumption. A significant $p$ value for the global test indicated violation of the proportional hazards assumption for the covariate [31]. Because Schoenfeld residuals assume that the effects of predictor variables are independent of time, a plot of Schoenfeld residuals against time was evaluated to determine whether the effect of the predictor variable changed during follow-up. Both the global test and plot assessment indicated that the proportional hazard assumptions were true for the dataset in the present study. The proportionality of the hazards of the treatment and case-mix variables was assessed. Specifically, we first obtained, by using logistic regression on different treatments, data for the following variables: age, sex, year of diagnosis, location of aneurysm, diabetes, congestive heart failure, hypertension, renal diseases, stroke or TIA, CCI scores, hospital level, hospital area, and income. All patients in the endovascular coil embolization group were matched at a 1:1 ratio with patients in the surgical clipping group through PSM by using global optimization [32]. Multivariate Cox regression analysis was performed to calculate hazard ratios (HRs) to determine whether any of the following variables were significant independent predictors: therapy type, age, sex, year of diagnosis, location of aneurysm, diabetes, congestive heart failure, hypertension, renal diseases, stroke or TIA, CCI score, hospital level, hospital area, and income. The independent predictors were controlled for in the analysis; the primary endpoint was the risk of re-rupture, and the secondary endpoints were the risks of vasospasm and re-stroke in the treatment groups, with surgical clipping serving as the control arm. The definition of vasospasm was a record of vasospasm in the same admission for the first aneurysmal SAH, re-stroke, or re-rupture. Vasospasm was also possibly encountered when receiving treatment for re-rupture or re-stroke after the first aneurysmal SAH. Therefore, the vasospasm might occur and be recorded when admissions of re-rupture or re-stroke undergo treatment.

The risk of complications was estimated using time-dependent Cox proportional hazard curves for vasospasm, re-stroke, and re-rupture in patients receiving different 
treatments. The hazards were estimated using a proportional subdistribution hazard regression model to overcome the competing risk of death that arises when analyzing the time-to-event data [33]. After we adjusted for confounders, we used the time-dependent Cox proportional hazards method to model the time from the index date to risk of complications. In the multivariate analysis, HRs were adjusted for age, sex, year of diagnosis, aneurysm locations, diabetes, congestive heart failure, hypertension, renal diseases, stroke or TIA previously, CCI score, hospital level, hospital area, and income. All analyses were performed using SAS version 9.3 (SAS Institute, Cary, NC, USA). A two-tailed $p<0.05$ was considered significant.

\section{Results}

After applying inclusion and exclusion criteria and PSM, 8102 patients (4051 each in the endovascular coil embolization and surgical clipping groups) were considered for analysis; their characteristics are summarized in Supplemental Table S1. Age, sex, year of diagnosis, aneurysm locations, diabetes, congestive heart failure, hypertension, renal diseases, stroke or TIA, CCI score, hospital level, hospital area, and income were similar in the two cohorts (Supplemental Table S1). All standardized differences of each covariate in Supplemental Table S1 were $<0.1$, indicating a balanced distribution between the two groups [34].

Multivariate Cox regression analysis revealed that treatment was the independent significant prognostic factor of re-rupture (Table 1). Both univariate and multivariate Cox regression analyses indicated that endovascular coil embolization was associated with a higher risk of re-rupture than surgical clipping (adjusted HR [aHR], 1.36; 95\% confidence interval [CI]: $1.17-1.57, p<0.0001)$. After PSM, no significant differences in covariates were observed for the primary endpoint of re-rupture (Table 1), and no residual imbalance or residual confounding bias was observed, indicating that our PSM was satisfactory $[35,36]$.

Table 1. Cox proportional hazards regression analysis of the risk of re-rupture among the propensity score-matched patients with ruptured subarachnoid aneurysms undergoing surgical clipping or endovascular coiling.

\begin{tabular}{|c|c|c|c|c|c|c|}
\hline & \multicolumn{3}{|c|}{ Univariate } & \multicolumn{3}{|c|}{ Multivariate } \\
\hline & HR & $(95 \% \mathrm{CI})$ & $p$ Value & AHR * & $(95 \% \mathrm{CI})$ & $p$ Value \\
\hline \multicolumn{7}{|l|}{ Aneurysm repair modalities } \\
\hline Surgical clipping & 1 & & $<0.0001$ & 1 & & $<0.0001$ \\
\hline $\begin{array}{c}\text { Endovascular coil } \\
\text { embolization } \\
\text { Age }\end{array}$ & 1.34 & $(1.16-1.55)$ & & 1.36 & $(1.17-1.57)$ & \\
\hline $20-64$ & 1 & & 0.2320 & 1 & & 0.5407 \\
\hline $65-74$ & 0.86 & $(0.71-1.04)$ & & 0.86 & $(0.71-1.05)$ & \\
\hline $75-84$ & 1.07 & $(0.43-1.77)$ & & 1.04 & $(0.40-1.17)$ & \\
\hline \multicolumn{7}{|l|}{ Sex } \\
\hline Female & 1 & & 0.5664 & 1 & & 0.9608 \\
\hline Male & 1.04 & $(0.90-1.21)$ & & 1.00 & $(0.86-1.17)$ & \\
\hline \multicolumn{7}{|l|}{ Treatment year } \\
\hline $2011-2013$ & 1 & & 0.0913 & 1 & & 0.1560 \\
\hline 2014-2015 & 1.05 & $(0.88-1.25)$ & & 1.07 & $(0.90-1.27)$ & \\
\hline $2016-2017$ & 0.86 & $(0.72-1.03)$ & & 0.89 & $(0.74-1.07)$ & \\
\hline Diabetes & 0.79 & $(0.63-0.99)$ & 0.0451 & 0.85 & $(0.67-1.07)$ & 0.1679 \\
\hline Congestive heart failure & 0.79 & $(0.46-1.37)$ & 0.3994 & 0.86 & $(0.49-1.51)$ & 0.5984 \\
\hline Hypertension & 0.91 & $(0.79-1.06)$ & 0.2222 & 1.08 & $(0.93-1.26)$ & 0.3318 \\
\hline \multicolumn{7}{|l|}{ Renal diseases } \\
\hline No renal diseases & 1 & & 0.2274 & 1 & & 0.5193 \\
\hline Chronic kidney disease & 0.90 & $(0.58-1.41)$ & & 1.01 & $(0.65-1.59)$ & \\
\hline End-stage renal disease & 1.74 & $(0.90-3.36)$ & & 1.49 & $(0.75-2.97)$ & \\
\hline Stroke or TIA & 0.83 & $(0.71-0.97)$ & 0.0175 & 0.91 & $(0.77-1.07)$ & 0.2479 \\
\hline \multicolumn{7}{|l|}{ CCI Scores } \\
\hline 0 & 1 & & $<0.4801$ & 1 & & 0.8913 \\
\hline
\end{tabular}


Table 1. Cont.

\begin{tabular}{|c|c|c|c|c|c|c|}
\hline & \multicolumn{3}{|c|}{ Univariate } & \multicolumn{3}{|c|}{ Multivariate } \\
\hline & HR & $(95 \% \mathrm{CI})$ & $p$ Value & AHR * & $(95 \% \mathrm{CI})$ & $p$ Value \\
\hline 1 & 1.04 & $(0.54-1.27)$ & & 1.01 & $(0.58-1.16)$ & \\
\hline $2+$ & 1.13 & $(0.51-1.28)$ & & 1.01 & $(0.56-1.19)$ & \\
\hline \multicolumn{7}{|l|}{ Hospital level } \\
\hline Academic centers & 1 & & 0.1815 & 1 & & 0.1847 \\
\hline Nonacademic centers & 0.88 & $(0.73-1.06)$ & & 0.88 & $(0.73-1.06)$ & \\
\hline \multicolumn{7}{|l|}{ Hospital area } \\
\hline North & 1 & & $<0.5562$ & 1 & & 0.6544 \\
\hline Central & 1.08 & $(0.56-1.54)$ & & 1.07 & $(0.56-1.44)$ & \\
\hline South/East & 1.05 & $(0.54-1.58)$ & & 1.04 & $(0.55-1.41)$ & \\
\hline \multicolumn{7}{|l|}{ Income } \\
\hline$<$ NTD 18,000 & 1 & & 0.4338 & 1 & & 0.5663 \\
\hline NTD 18,000-22,500 & 1.09 & $(0.88-1.35)$ & & 1.12 & $(0.90-1.40)$ & \\
\hline NTD 22,500-30,000 & 0.93 & $(0.74-1.16)$ & & 0.96 & $(0.77-1.20)$ & \\
\hline NTD 30,000+ & 1.08 & $(0.89-1.31)$ & & 1.02 & $(0.84-1.25)$ & \\
\hline
\end{tabular}

CCI, Charlson Comorbidity Index; SD, standard deviation; IQR, interquartile range; NTD, New Taiwan dollar; TIA, transient ischemic attack; CI, confidence interval; AHR, adjusted hazard ratio; HR, hazard ratio. * adjusted for all covariates mentioned in this table.

The aHR $(95 \% \mathrm{CI})$ of vasospasm for endovascular coil embolization compared with surgical clipping was $1.14(1.02-1.27), p=0.0214$. The aHRs $(95 \% \mathrm{CI})$ of vasospasm for the age groups of 65-74, 75-84, and 85+ years compared with the age group of 20-64 years were 1.27 (1.11-1.46), 1.40 (1.19-1.66), and 1.07 (1.01-1.53), respectively. The aHRs (95\% CI) of vasospasm for men and patients with diabetes, congestive heart failure, hypertension, and stroke or TIA history were 1.22 (1.10-1.37), 1.20 (1.04-1.39), 1.30 (1.06-1.76), 1.17 (1.04-1.32), and 1.27 (1.14-1.43) compared with women and patients without diabetes, congestive heart failure, hypertension, and stroke or TIA history, respectively.

The aHR (95\% CI) of re-stroke (delayed cerebral ischemia) for endovascular coil embolization compared with surgical clipping was $2.04(1.83-2.29), p<0.0001$. The aHRs $(95 \% \mathrm{CI})$ of re-stroke for the age groups of $65-74,75-84$, and $85+$ years compared with the age group of 20-64 years were 1.10 (1.06-1.26), 1.21 (1.04-1.20), and $1.22(1.15-1.52)$, respectively. The aHRs $(95 \% \mathrm{CI})$ of re-stroke for men and patients with diabetes, congestive heart failure, hypertension, and stroke or TIA history were 1.06 (1.01-1.19), 1.21 (1.05-1.40), 1.26 (1.11-1.73), $1.14(1.02-1.28)$, and $1.27(1.13-1.42)$ compared with women and patients without diabetes, congestive heart failure, hypertension, and stroke or TIA history, respectively. Thus, endovascular coil embolization, male sex, older age ( $\geq 65$ years), diabetes, congestive heart failure, hypertension, and stroke or TIA history were independent poor prognostic factors of both vasospasm and re-stroke (Tables 2 and 3).

Table 2. Cox proportional hazards regression analysis of the risk of vasospasm among the propensity score-matched patients with ruptured subarachnoid aneurysm undergoing surgical clipping or endovascular coiling.

\begin{tabular}{|c|c|c|c|c|c|c|}
\hline & \multicolumn{3}{|c|}{ Univariate } & \multicolumn{3}{|c|}{ Multivariate } \\
\hline & HR & $(95 \% \mathrm{CI})$ & $p$ Value & AHR * & $(95 \% \mathrm{CI})$ & $p$ Value \\
\hline \multicolumn{7}{|c|}{ Aneurysm repair modalities } \\
\hline Surgical clipping & 1 & & 0.0050 & 1 & & 0.0214 \\
\hline $\begin{array}{c}\text { Endovascular coil } \\
\text { embolization } \\
\text { Age }\end{array}$ & 1.17 & $(1.05-1.30)$ & & 1.14 & $(1.02-1.27)$ & \\
\hline $20-64$ & 1 & & $<0.0001$ & 1 & & $<0.0001$ \\
\hline $65-74$ & 1.45 & $(1.27-1.66)$ & & 1.27 & $(1.11-1.46)$ & \\
\hline $75-84$ & 1.78 & $(1.52-2.08)$ & & 1.40 & $(1.19-1.66)$ & \\
\hline $\begin{array}{l}85+ \\
\text { Sex }\end{array}$ & 1.38 & $(1.08-2.18)$ & & 1.07 & $(1.01-1.53)$ & \\
\hline Female & 1 & & 0.0020 & 1 & & 0.0004 \\
\hline Male & 1.19 & $(1.07-1.33)$ & & 1.22 & $(1.10-1.37)$ & \\
\hline
\end{tabular}


Table 2. Cont.

\begin{tabular}{|c|c|c|c|c|c|c|}
\hline & \multicolumn{3}{|c|}{ Univariate } & \multicolumn{3}{|c|}{ Multivariate } \\
\hline & HR & $(95 \% \mathrm{CI})$ & $p$ Value & AHR * & $(95 \% \mathrm{CI})$ & $p$ Value \\
\hline \multicolumn{7}{|l|}{ Treatment year } \\
\hline 2011-2013 & 1 & & 0.3838 & 1 & & 0.1567 \\
\hline $2014-2015$ & 0.96 & $(0.84-1.10)$ & & 0.94 & $(0.82-1.07)$ & \\
\hline 2016-2017 & 0.91 & $(0.80-1.04)$ & & 0.87 & $(0.75-1.00)$ & \\
\hline Diabetes & 1.47 & $(1.28-1.68)$ & $<0.0001$ & 1.20 & $(1.04-1.39)$ & 0.0141 \\
\hline Congestive heart failure & 1.69 & $(1.16-2.27)$ & 0.0005 & 1.30 & $(1.06-1.76)$ & 0.0297 \\
\hline Hypertension & 1.35 & $(1.21-1.51)$ & $<0.0001$ & 1.17 & $(1.04-1.32)$ & 0.0089 \\
\hline \multicolumn{7}{|l|}{ Renal diseases } \\
\hline No renal diseases & 1 & & 0.0364 & 1 & & 0.2182 \\
\hline Chronic kidney disease & 1.43 & $(1.09-1.89)$ & & 1.09 & $(0.82-1.44)$ & \\
\hline End-stage renal disease & 1.09 & $(0.58-2.02)$ & & 0.60 & $(0.32-1.11)$ & \\
\hline Stroke or TIA & 1.31 & $(1.18-1.46)$ & $<0.0001$ & 1.27 & $(1.14-1.43)$ & $<0.0001$ \\
\hline \multicolumn{7}{|l|}{ CCI Scores } \\
\hline 0 & 1 & & 0.3241 & 1 & & 0.6873 \\
\hline 1 & 0.91 & $(0.78-1.07)$ & & 1.01 & $(0.68-1.05)$ & \\
\hline $2+$ & 1.30 & $(0.90-1.54)$ & & 1.02 & $(0.85-1.22)$ & \\
\hline \multicolumn{7}{|l|}{ Hospital level } \\
\hline Academic centers & 1 & & 0.7209 & 1 & & 0.1738 \\
\hline Nonacademic centers & 0.98 & $(0.85-1.12)$ & & 0.91 & $(0.79-1.04)$ & \\
\hline \multicolumn{7}{|l|}{ Hospital area } \\
\hline North & 1 & & 0.4004 & 1 & & 0.0570 \\
\hline Central & 0.90 & $(0.78-1.05)$ & & 0.84 & $(0.72-1.07)$ & \\
\hline South/East & 0.96 & $(0.85-1.10)$ & & 0.96 & $(0.84-1.10)$ & \\
\hline Income & & & & & & \\
\hline$<$ NTD 18,000 & 1 & & 0.0006 & 1 & & 0.1133 \\
\hline NTD $18,000-22,500$ & 1.00 & $(0.86-1.17)$ & & 1.05 & $(0.90-1.23)$ & \\
\hline NTD 22,500-30,000 & 0.97 & $(0.82-1.13)$ & & 1.04 & $(0.88-1.22)$ & \\
\hline NTD $30,000+$ & 0.77 & $(0.66-0.89)$ & & 1.04 & $(0.73-1.08)$ & \\
\hline
\end{tabular}

CCI, Charlson Comorbidity Index; SD, standard deviation; IQR, interquartile range; NTD, New Taiwan dollar; TIA, transient ischemic attack; CI, confidence interval; AHR, adjusted hazard ratio; HR, hazard ratio. * adjusted for all covariates mentioned in Table 1.

Figures 1-3 present re-rupture-free, vasospasm-free, and re-stroke-free Kaplan-Meier survival curves in our cohort of patients with aneurysmal SAH. In general, patients undergoing surgical clipping had better survival than those undergoing coil embolization. The 1-year and 5-year re-rupture-free survival rates for surgical clipping and coil embolization were $94.3 \%$ and $92.4 \%$ and $91.2 \%$ and $89.5 \%$, respectively $(p<0.0001$; Figure 1$)$. The risk of re-rupture was the highest in the first postoperative year and decreased gradually every year, irrespective of the treatment. The 1-year and 5-year vasospasm-free survival rates for surgical clipping and coil embolization were $88.7 \%$ and $86.7 \%$ and $85.4 \%$ and $84.1 \%$, respectively $(p<0.0049$; Figure 2$)$. The risk of vasospasm was highest after the initial hemorrhage, irrespective of the treatment. The 1-year and 5-year re-stroke-free survival rates for surgical clipping and coil embolization were $95.4 \%$ and $88.3 \%$ and $86.1 \%$ and $74.5 \%$, respectively ( $p<0.0001$; Figure 3 ). The annual risk of re-stroke continued to be high, irrespective of the treatment. 


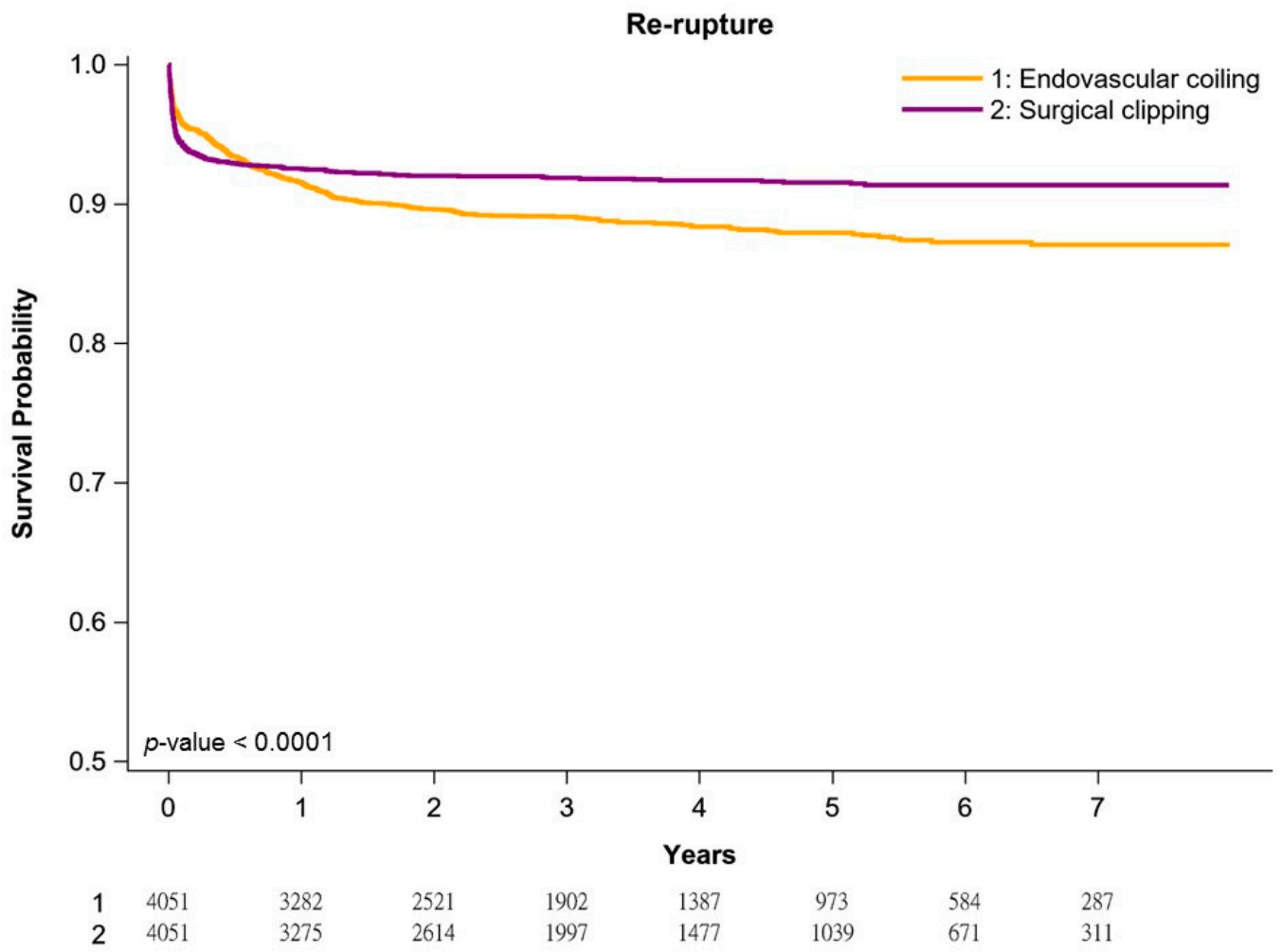

Figure 1. Kaplan-Meier re-rupture-free survival curves of propensity score-matched patients.

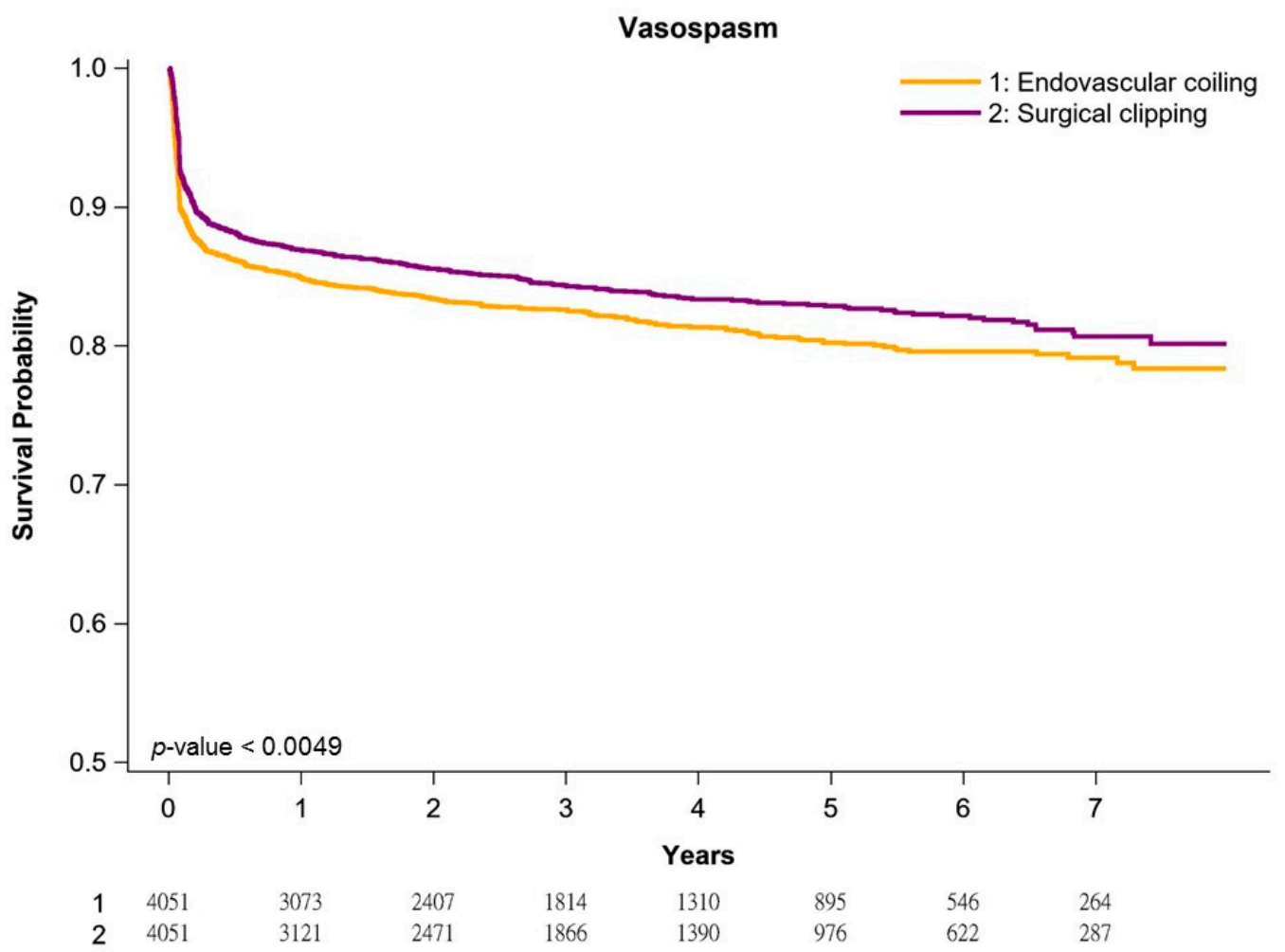

Figure 2. Kaplan-Meier vasospasm-free survival curves of propensity score-matched patients. 


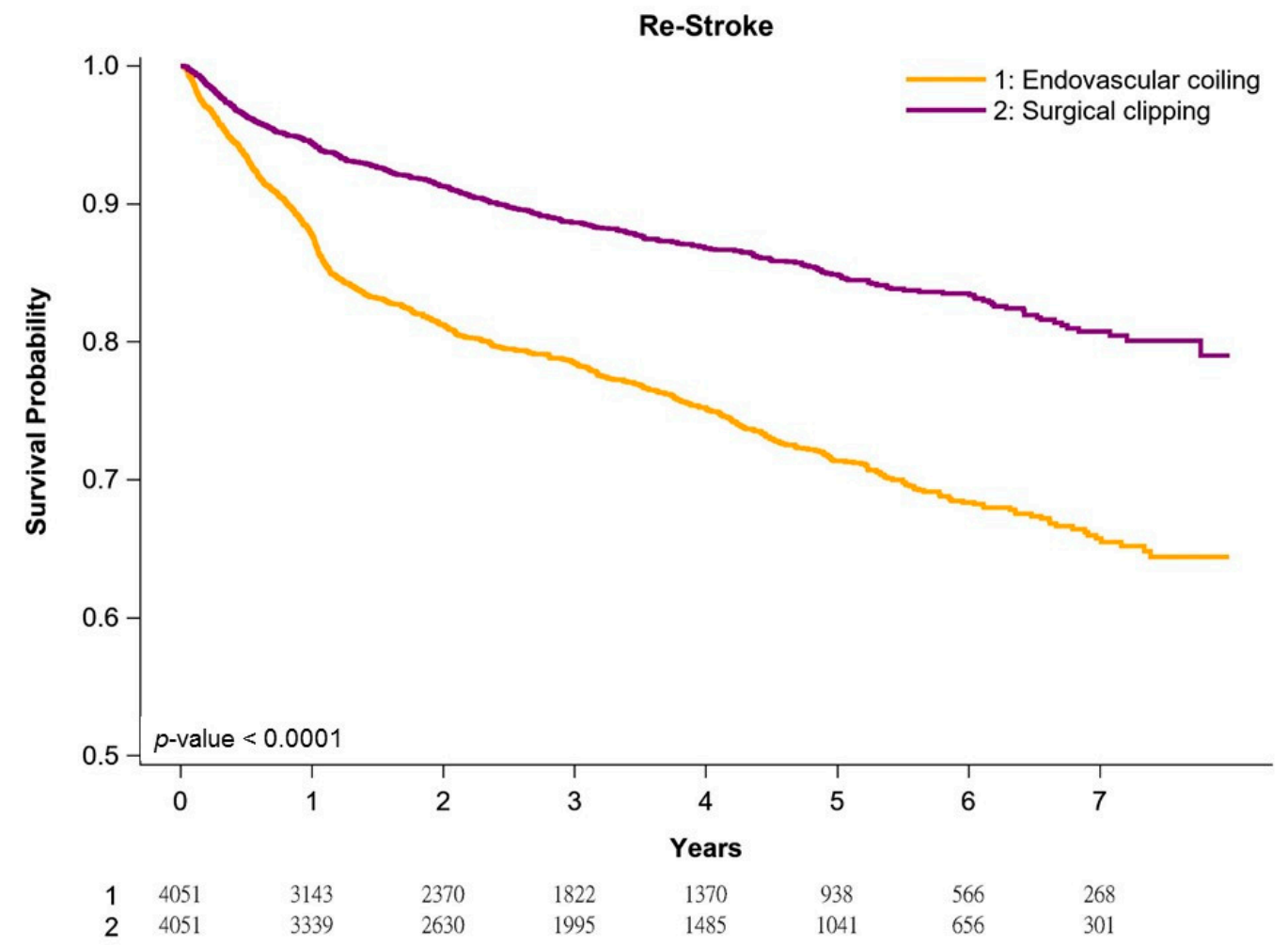

Figure 3. Kaplan-Meier re-stroke-free survival curves of propensity score-matched patients.

Table 3. Cox proportional hazards regression analysis of the risk of re-stroke among propensity score-matched patients with ruptured subarachnoid aneurysm undergoing surgical clipping or endovascular coiling.

\begin{tabular}{|c|c|c|c|c|c|c|}
\hline & \multicolumn{3}{|c|}{ Univariate } & \multicolumn{3}{|c|}{ Multivariate } \\
\hline & HR & $(95 \% \mathrm{CI})$ & $p$ Value & AHR * & $(95 \% \mathrm{CI})$ & $p$ Value \\
\hline \multicolumn{7}{|l|}{ Aneurysm repair modalities } \\
\hline Surgical clipping & 1 & & $<0.0001$ & 1 & & $<0.0001$ \\
\hline $\begin{array}{l}\text { Endovascular coil } \\
\text { embolization }\end{array}$ & 2.08 & $(1.86-2.32)$ & & 2.04 & $(1.83-2.29)$ & \\
\hline \multicolumn{7}{|l|}{ Age } \\
\hline $20-64$ & 1 & & $<0.0001$ & 1 & & 0.0135 \\
\hline $65-74$ & 1.30 & $(1.14-1.48)$ & & 1.10 & $(1.06-1.26)$ & \\
\hline $75-84$ & 1.50 & $(1.27-1.77)$ & & 1.21 & $(1.04-1.20)$ & \\
\hline $85+$ & 1.22 & $(1.12-2.06)$ & & 1.22 & $(1.15-1.52)$ & \\
\hline \multicolumn{7}{|l|}{ Sex } \\
\hline Female & 1 & & 0.1537 & 1 & & 0.0416 \\
\hline Male & 1.08 & $(0.97-1.21)$ & & 1.06 & $(1.01-1.19)$ & \\
\hline \multicolumn{7}{|l|}{ Treatment year } \\
\hline 2011-2013 & 1 & & $<0.7911$ & 1 & & $<0.8801$ \\
\hline 2014-2015 & 0.91 & $(0.97-2.66)$ & & 0.95 & $(0.70-2.23)$ & \\
\hline 2016-2017 & 0.78 & $(0.84-4.41)$ & & 0.91 & $(0.84-3.34)$ & \\
\hline Diabetes & 1.45 & $(1.26-1.66)$ & $<0.0001$ & 1.21 & $(1.05-1.40)$ & 0.0099 \\
\hline Congestive heart failure & 1.75 & $(1.29-2.36)$ & 0.0003 & 1.26 & $(1.11-1.73)$ & 0.0151 \\
\hline Hypertension & 1.23 & $(1.11-1.37)$ & $<0.0001$ & 1.14 & $(1.02-1.28)$ & 0.0239 \\
\hline \multicolumn{7}{|l|}{ Renal diseases } \\
\hline No renal diseases & 1 & & 0.0053 & 1 & & 0.7824 \\
\hline Chronic kidney disease & 1.35 & $(1.01-1.80)$ & & 0.94 & $(0.70-1.28)$ & \\
\hline End-stage renal disease & 2.00 & $(1.18-3.38)$ & & 0.84 & $(0.49-1.46)$ & \\
\hline Stroke or TIA & 1.26 & $(1.13-1.40)$ & $<0.0001$ & 1.27 & $(1.13-1.42)$ & $<0.0001$ \\
\hline \multicolumn{7}{|l|}{ CCI Scores } \\
\hline 0 & 1 & & 0.5607 & 1 & & 0.3244 \\
\hline 1 & 0.78 & $(0.67-1.90)$ & & 0.84 & $(0.72-1.48)$ & \\
\hline
\end{tabular}


Table 3. Cont.

\begin{tabular}{|c|c|c|c|c|c|c|}
\hline & \multicolumn{3}{|c|}{ Univariate } & \multicolumn{3}{|c|}{ Multivariate } \\
\hline & HR & $(95 \% \mathrm{CI})$ & $p$ Value & AHR * & $(95 \% \mathrm{CI})$ & $p$ Value \\
\hline $\begin{array}{c}2+ \\
\text { Hospital level }\end{array}$ & 0.91 & $(0.78-1.07)$ & & 0.79 & $(0.67-1.44)$ & \\
\hline $\begin{array}{l}\text { Medical center } \\
\text { others }\end{array}$ & $\begin{array}{c}1 \\
1.08\end{array}$ & $(0.95-1.23)$ & 0.2219 & $\begin{array}{c}1 \\
0.97\end{array}$ & $(0.85-1.11)$ & 0.6973 \\
\hline Hospital area & & & & & & \\
\hline North & 1 & & 0.5405 & 1 & & $<0.6611$ \\
\hline Central & 1.06 & $(0.66-1.88)$ & & 1.03 & $(0.58-1.78)$ & \\
\hline $\begin{array}{l}\text { South/East } \\
\text { Income }\end{array}$ & 1.08 & $(0.60-1.78)$ & & 1.04 & $(0.56-1.73)$ & \\
\hline$<$ NTD 18,000 & 1 & & $<0.0001$ & 1 & & 0.2340 \\
\hline NTD $18,000-22,500$ & 0.80 & $(0.68-0.94)$ & & 1.05 & $(0.89-1.25)$ & \\
\hline NTD 22,500-30,000 & 1.35 & $(1.16-1.57)$ & & 1.17 & $(1.00-1.37)$ & \\
\hline NTD 30,000+ & 0.97 & $(0.84-1.13)$ & & 1.04 & $(0.89-1.20)$ & \\
\hline
\end{tabular}

CCI, Charlson Comorbidity Index; SD, standard deviation; IQR, interquartile range; NTD, New Taiwan dollar; TIA, transient ischemic attack; CI, confidence interval; AHR, adjusted hazard ratio; HR, hazard ratio. * adjusted for all covariates mentioned in Table 1.

\section{Discussion}

Surgical clipping and endovascular coiling are the most commonly used treatments for aneurysmal SAH [1-3]. In one study, the rate of re-rupture in patients with aneurysmal SAH undergoing endovascular coiling was higher in the first postoperative year than in subsequent years $(2.6 \%$ versus $1.0 \%)$ [33]. Only a few re-rupture events occurred in either treatment group after 1 year, but this was more common in the endovascular coiling group than in the surgical clipping group [33]. In another study, within 8 years, the re-rupture rates were comparable in both groups [37]. Among patients with aneurysmal SAH who reach the hospital alive, early in-hospital mortality is typically caused by the common complications of aneurysmal SAH, namely re-rupture, vasospasm, and re-stroke [38-40]. Angiographic (proximal) vasospasm is a risk factor for delayed cerebral ischemia, but is probably not the direct culprit $[17,18]$. In the early posttreatment phase, vasospasm typically begins no earlier than day 3 after hemorrhage, reaching a peak at days 7 to $8[9,10,41,42]$. Although re-stroke contributes substantially to morbidity and mortality [14,15], no significant association was found between vasospasm and patient outcome. [43]. Other major complications include elevated intracranial pressure related to hydrocephalus or other causes, hyponatremia, seizure, and spreading depolarizations [38-40,44]. However, no studies have analyzed the long-term (late-phase) outcomes or prognostic factors of complications such as re-rupture, vasospasm, and re-stroke in patients with aneurysmal SAH receiving coil embolization or surgical clipping, especially in Asia. Understanding the outcomes and prognostic factors of acute and chronic complications is valuable for facilitating shared decision-making by physicians and patients.

In our cohort, no residual imbalance was observed between the two treatment groups (Supplemental Table S1), which explains why no significant factors were noted for the risk of re-rupture (Table 1). Our well-matched PSM design may explain the lack of selection bias in age, sex, year of diagnosis, location of aneurysm, diabetes, congestive heart failure, hypertension, renal diseases, stroke or TIA, CCI score, hospital level, hospital area, and income between the two treatment groups. The crude long-term risks of re-rupture, vasospasm, and re-stroke from 1 January 2011, to 31 December 2017 were 10.5\% and 7.8\%, $17.2 \%$ and $15.2 \%$, and $22.7 \%$ and $11.7 \%$ for coil embolization and surgical clipping, respectively. More long-term complications of re-rupture, vasospasm, and re-stroke were noted in the endovascular coil embolization group than in the surgical clipping group. Re-rupture of the treated aneurysm occurs in $9 \%-34 \%$ of endovascularly treated aneurysms [45-47]. Our results agree with those of studies on re-rupture in patients with aneurysmal SAH receiving endovascular coil embolization or surgical clipping [45-47]. Previous studies on vasospasm and re-stroke included only in-hospital data and did not perform long-term 
follow-ups. Our study is the first to estimate the long-term risk and prognostic factors of complications for patients with aneurysmal SAH receiving endovascular coil embolization or surgical clipping.

The long-term risk of re-rupture between endovascular coil embolization and surgical clipping observed in the present study is compatible with that reported in previous studies [45-47]. In the current study, most cases of re-rupture occurred in the first postoperative year irrespective of the treatment; after the first year, re-rupture was rare in the surgical clipping group, but still occurred in the endovascular coil embolization group. Our findings are similar to those of a previous Western study, which indicated few re-rupture events in either treatment group after 1 year, but those that occurred were more common in the coiling group [45]. Our study is the first study from Asia to demonstrate a similar trend of re-rupture between endovascular coil embolization and surgical clipping for patients with aneurysmal SAH; however, the risk of re-rupture in our cohort was higher than that observed in the Western study [45]. Moreover, the prognostic factors of re-rupture were not significant in our study because of a lack of residual imbalance between the two groups after PSM [35,36], meaning that no selection bias was noted for therapeutic choice of endovascular coil embolization or surgical clipping in patients with Hunt and Hess grades I-III aneurysmal SAH in our study.

Consistent with previous studies [9,10,41,42], our data indicated that the risk of vasospasm was the highest after the initial hemorrhage. However, some patients still developed re-rupture or re-stroke combined with vasospasm after the first treatment, and the risk continued to increase even after 7 years of follow up (Figure 2). Our study is the first to evaluate the long-term risk of first vasospasm and sequential vasospasm of the first aneurysmal SAH, re-rupture or re-stroke when receiving treatment in patients with aneurysmal SAH undergoing endovascular coil embolization or surgical clipping. In addition, multivariable Cox regression analysis indicated that the following factors were independent poor prognostic factors of vasospasm: endovascular coil embolization, male sex, older age ( $\geq 65$ years; the risk of vasospasm increased with age), hypertension, congestive heart failure, diabetes, and previous TIA or stroke (Table 2). Previous studies have also indicated diabetes as the independent poor prognostic factor of vasospasm [48,49]. Several short-term retrospective studies with small sample sizes have revealed conflicting results regarding the association of endovascular coiling with the risk of vasospasm [50-55]. Our well-designed PSM study with a large sample size, long-term follow-up, and potentially no selection bias indicated that endovascular coiling is an independent risk factor for vasospasm (Table 2).

Re-stroke is considered when focal neurologic impairment occurs, which was not apparent immediately after aneurysm occlusion and cannot be attributed to other causes after appropriate clinical assessment, brain imaging, and laboratory studies [56]. The most common cause of re-stroke after aneurysmal SAH is assumed to be vasospasm [16]. In our study, unlike re-rupture or vasospasm, the risk of re-stroke was not the highest in the first postoperative year and did not decrease or plateau even after 7 years of followup (Figure 3). This could be a regional problem in Taiwan. In the near future, we will investigate in more depth what underlies the unusually high stroke rate in the long term. The first thing to investigate in the future is whether procedures are performed differently in Taiwan than in other countries and whether the differences in these infarcts that occur after years are found only in certain hospitals or in all hospitals. Our findings suggest that Taiwanese patients with aneurysmal SAH receiving treatment should be monitored in the long term for risk of re-stroke, given the crude incidence of $22.7 \%$ and $11.7 \%$ for endovascular coil embolization and surgical clipping, respectively (Supplemental Table S1). The independent poor prognostic factors for re-stroke were similar to those of vasospasm, which may be because vasospasm is strongly associated with re-stroke [14-16]. Our study is the first to estimate the prognostic factors of re-stroke in patients with aneurysmal SAH receiving endovascular coil embolization or surgical clipping after head-to-head PSM and long-term follow-up. 
The strengths of this study are its large sample size, long-term follow-up, and the homogeneity of the ruptured intracranial aneurysms population with good-grade aneurysmal SAH, with no heterogeneity in the following covariates: age, sex, year of diagnosis, aneurysm locations, diabetes, congestive heart failure, hypertension, renal diseases, stroke or TIA, CCI score, hospital level, hospital area, and income. Most major covariates were considered in the PSM analysis. This is the first and largest head-to-head PSM study to estimate the long-term major complications of endovascular coil embolization or surgical clipping for patients with aneurysmal SAH. In our findings, endovascular coil embolization had a higher risk than surgical clipping for ruptured intracranial aneurysm. In addition, endovascular coil embolization, male sex, older age ( $\geq 65$ years), hypertension, congestive heart failure, diabetes, and previous TIA or stroke were independent poor prognostic factors of vasospasm or re-stroke. These findings should be considered in future clinical practice and prospective clinical trials.

This study has some limitations. First, because all patients with aneurysmal SAH were enrolled from an Asian population, our results should be cautiously extrapolated to non-Asian populations in non-areca prevalence areas. Second, the population is aging; instead of vasospasm, there could be the development of atherosclerotic changes in the cerebral arteries, which increase with age in any population. It is possible that such cases were incorrectly assessed as vasospasm because the investigator knew that the patients once had a history of SAH. Therefore, the risk of vasospasm several years after the initial hemorrhage was possibly overestimated. Third, the diagnoses of all comorbid conditions were based on ICD-9-CM codes, which may be entered incorrectly. However, Taiwan's National Health Insurance Research Administration randomly reviews charts and interviews patients to verify the accuracy of the diagnoses, and hospitals with outlier charges or practices may be audited and subsequently be heavily penalized if malpractice or discrepancies are identified. Nevertheless, a large-scale randomized trial comparing carefully selected patients undergoing suitable treatments is essential to obtain crucial information on population specificity and disease occurrence. Finally, the NHIRD does not contain information regarding dietary habits, socioeconomic status, or body mass index, all of which may be risk factors for mortality. However, considering the magnitude and statistical significance of the observed effects in this study, these limitations are unlikely to affect the results.

\section{Conclusions}

Endovascular coil embolization has a higher risk than surgical clipping for ruptured intracranial aneurysm in terms of acute and long-term complications including re-rupture, vasospasm, and re-stroke. In addition, endovascular coil embolization, male sex, older age ( $\geq 65$ years; risk increases with age), hypertension, congestive heart failure, diabetes, and previous TIA or stroke were independent poor prognostic factors of vasospasm and re-stroke.

Supplementary Materials: The following are available online at https:/ /www.mdpi.com/article/10 .3390/jpm11111209/s1, Table S1: Demographic and clinical parameters of Propensity Score Matching patients with rupture intracranial aneurysm.

Author Contributions: Conception and Design: J.Z., Y.-L.L., M.-C.L., Y.-H.Y., S.-Y.W.; Collection and Assembly of Data: J.Z., Y.-L.L., Y.-H.Y., S.-Y.W.; Data Analysis and Interpretation: J.Z., Y.-L.L., M.-C.L.; Administrative Support: S.-Y.W.; Manuscript Writing: All authors; Final Approval of Manuscript: All authors. All authors have read and agreed to the published version of the manuscript.

Funding: This research received no external funding.

Institutional Review Board Statement: The study protocols were reviewed and approved by the Institutional Review Board of Tzu-Chi Medical Foundation (IRB109-015-B).

Informed Consent Statement: Not applicable. 
Data Availability Statement: The datasets supporting the study conclusions are included in this manuscript and its Supplementary Files.

Acknowledgments: Lo-Hsu Medical Foundation, LotungPoh-Ai Hospital, supports Szu-Yuan Wu's work (Funding Number: 10908, 10909, 11001, 11002, 11003, 11006, and 11013).

Conflicts of Interest: The authors have no potential conflict of interest to declare. The datasets supporting the study conclusions are included within the manuscript.

\section{References}

1. $\quad$ Bederson, J.B.; Connolly, E.S., Jr.; Batjer, H.H.; Dacey, R.G.; Dion, J.E.; Diringer, M.N.; Duldner, J.E., Jr.; Harbaugh, R.E.; Patel, A.B.; Rosenwasser, R.H.; et al. Guidelines for the management of aneurysmal subarachnoid hemorrhage: A statement for healthcare professionals from a special writing group of the Stroke Council, American Heart Association. Stroke 2009, 40, $994-1025$. [CrossRef] [PubMed]

2. Connolly, E.S., Jr.; Rabinstein, A.A.; Carhuapoma, J.R.; Derdeyn, C.P.; Dion, J.; Higashida, R.T.; Hoh, B.L.; Kirkness, C.J.; Naidech, A.M.; Ogilvy, C.S.; et al. Guidelines for the management of aneurysmal subarachnoid hemorrhage: A guideline for healthcare professionals from the American Heart Association/american Stroke Association. Stroke 2012, 43, 1711-1737. [CrossRef] [PubMed]

3. Dovey, Z.; Misra, M.; Thornton, J.; Charbel, F.T.; Debrun, G.M.; Ausman, J.I. Guglielmi detachable coiling for intracranial aneurysms: The story so far. Arch. Neurol. 2001, 58, 559-564. [CrossRef]

4. Francoeur, C.L.; Mayer, S.A. Management of delayed cerebral ischemia after subarachnoid hemorrhage. Crit. Care 2016, $20,277$. [CrossRef]

5. Hillman, J.; Fridriksson, S.; Nilsson, O.; Yu, Z.; Saveland, H.; Jakobsson, K.E. Immediate administration of tranexamic acid and reduced incidence of early rebleeding after aneurysmal subarachnoid hemorrhage: A prospective randomized study. J. Neurosurg. 2002, 97, 771-778. [CrossRef] [PubMed]

6. Naidech, A.M.; Janjua, N.; Kreiter, K.T.; Ostapkovich, N.D.; Fitzsimmons, B.F.; Parra, A.; Commichau, C.; Connolly, E.S.; Mayer, S.A. Predictors and impact of aneurysm rebleeding after subarachnoid hemorrhage. Arch. Neurol. 2005, 62, 410-416. [CrossRef]

7. Ohkuma, H.; Tsurutani, H.; Suzuki, S. Incidence and significance of early aneurysmal rebleeding before neurosurgical or neurological management. Stroke 2001, 32, 1176-1180. [CrossRef]

8. Kassell, N.F.; Torner, J.C. Aneurysmal rebleeding: A preliminary report from the Cooperative Aneurysm Study. Neurosurgery 1983, 13, 479-481. [CrossRef]

9. Wilkins, R.H. Aneurysm rupture during angiography: Does acute vasospasm occur? Surg. Neurol. 1976, 5, $299-303$.

10. Baldwin, M.E.; Macdonald, R.L.; Huo, D.; Novakovic, R.L.; Goldenberg, F.D.; Frank, J.I.; Rosengart, A.J. Early vasospasm on admission angiography in patients with aneurysmal subarachnoid hemorrhage is a predictor for in-hospital complications and poor outcome. Stroke 2004, 35, 2506-2511. [CrossRef]

11. Suarez, J.I. Diagnosis and Management of Subarachnoid Hemorrhage. Continuum (Minneap Minn) 2015, 21, 1263-1287. [CrossRef]

12. Rowland, M.J.; Hadjipavlou, G.; Kelly, M.; Westbrook, J.; Pattinson, K.T. Delayed cerebral ischaemia after subarachnoid haemorrhage: Looking beyond vasospasm. Br. J. Anaesth. 2012, 109, 315-329. [CrossRef] [PubMed]

13. Helbok, R.; Kurtz, P.; Vibbert, M.; Schmidt, M.J.; Fernandez, L.; Lantigua, H.; Ostapkovich, N.D.; Connolly, S.E.; Lee, K.; Claassen, J.; et al. Early neurological deterioration after subarachnoid haemorrhage: Risk factors and impact on outcome. J. Neurol. Neurosurg. Psychiatry 2013, 84, 266-270. [CrossRef]

14. Rosengart, A.J.; Schultheiss, K.E.; Tolentino, J.; Macdonald, R.L. Prognostic factors for outcome in patients with aneurysmal subarachnoid hemorrhage. Stroke 2007, 38, 2315-2321. [CrossRef]

15. Macdonald, R.L.; Hunsche, E.; Schuler, R.; Wlodarczyk, J.; Mayer, S.A. Quality of life and healthcare resource use associated with angiographic vasospasm after aneurysmal subarachnoid hemorrhage. Stroke 2012, 43, 1082-1088. [CrossRef]

16. Rabinstein, A.A.; Friedman, J.A.; Weigand, S.D.; McClelland, R.L.; Fulgham, J.R.; Manno, E.M.; Atkinson, J.L.; Wijdicks, E.F. Predictors of cerebral infarction in aneurysmal subarachnoid hemorrhage. Stroke 2004, 35, 1862-1866. [CrossRef] [PubMed]

17. Luckl, J.; Lemale, C.L.; Kola, V.; Horst, V.; Khojasteh, U.; Oliveira-Ferreira, A.I.; Major, S.; Winkler, M.K.L.; Kang, E.J.; Schoknecht, K.; et al. The negative ultraslow potential, electrophysiological correlate of infarction in the human cortex. Brain 2018, 141, 1734-1752. [CrossRef] [PubMed]

18. Dreier, J.P. The role of spreading depression, spreading depolarization and spreading ischemia in neurological disease. Nat. Med. 2011, 17, 439-447. [CrossRef]

19. Wen, C.P.; Tsai, S.P.; Chung, W.S. A 10-year experience with universal health insurance in Taiwan: Measuring changes in health and health disparity. Ann. Intern. Med. 2008, 148, 258-267. [CrossRef]

20. Shao, Y.J.; Chan, T.S.; Tsai, K.; Wu, S.Y. Association between proton pump inhibitors and the risk of hepatocellular carcinoma. Aliment. Pharmacol. Ther. 2018, 48, 460-468. [CrossRef]

21. Lin, W.C.; Ding, Y.F.; Hsu, H.L.; Chang, J.H.; Yuan, K.S.; Wu, A.T.H.; Chow, J.M.; Chang, C.L.; Chen, S.U.; Wu, S.Y. Value and application of trimodality therapy or definitive concurrent chemoradiotherapy in thoracic esophageal squamous cell carcinoma. Cancer 2017, 123, 3904-3915. [CrossRef] 
22. Yen, Y.C.; Chang, J.H.; Lin, W.C.; Chiou, J.F.; Chang, Y.C.; Chang, C.L.; Hsu, H.L.; Chow, J.M.; Yuan, K.S.; Wu, A.T.H.; et al. Effectiveness of esophagectomy in patients with thoracic esophageal squamous cell carcinoma receiving definitive radiotherapy or concurrent chemoradiotherapy through intensity-modulated radiation therapy techniques. Cancer 2017, 123, 2043-2053. [CrossRef] [PubMed]

23. Chang, S.C.; Chen, H.M.; Wu, S.Y. There Are No Differences in Positive Surgical Margin Rates or Biochemical Failure-Free Survival among Patients Receiving Open, Laparoscopic, or Robotic Radical Prostatectomy: A Nationwide Cohort Study from the National Cancer Database. Cancers 2020, 13, 106. [CrossRef] [PubMed]

24. Chang, S.C.; Hsu, C.H.; Lin, Y.C.; Wu, S.Y. Effects of 1-Year Hospital Volume on Surgical Margin and Biochemical-Failure-Free Survival in Patients Undergoing Robotic versus Nonrobotic Radical Prostatectomy: A Nationwide Cohort Study from the National Taiwan Cancer Database. Cancers 2021, 13, 488. [CrossRef]

25. Wu, S.Y.; Fang, S.C.; Shih, H.J.; Wen, Y.C.; Shao, Y.J. Mortality associated with statins in men with advanced prostate cancer treated with androgen deprivation therapy. Eur. J. Cancer 2019, 112, 109-117. [CrossRef] [PubMed]

26. Liu, W.C.; Liu, H.E.; Kao, Y.W.; Qin, L.; Lin, K.C.; Fang, C.Y.; Tsai, L.L.; Shia, B.C.; Wu, S.Y. Definitive intensity-modulated radiotherapy or surgery for early oral cavity squamous cell carcinoma: Propensity-score-matched, nationwide, population-based cohort study. Head Neck 2020. [CrossRef] [PubMed]

27. Liu, J.C.; Wang, T.J.; Sung, L.C.; Kao, P.F.; Yang, T.Y.; Hao, W.R.; Chen, C.C.; Hsu, Y.P.; Wu, S.Y. Influenza vaccination reduces hemorrhagic stroke risk in patients with atrial fibrillation: A population-based cohort study. Int. J. Cardiol. 2017, 232, 315-323. [CrossRef]

28. Lin, K.C.; Tsai, L.L.; Ko, E.C.; Sheng-Po Yuan, K.; Wu, S.Y. Comorbidity profiles among patients with recurrent aphthous stomatitis: A case-control study. J. Formos. Med. Assoc. 2019, 118, 664-670. [CrossRef]

29. Charlson, M.; Szatrowski, T.P.; Peterson, J.; Gold, J. Validation of a combined comorbidity index. J. Clin. Epidemiol. 1994, 47, 1245-1251. [CrossRef]

30. Chen, J.H.; Yen, Y.C.; Yang, H.C.; Liu, S.H.; Yuan, S.P.; Wu, L.L.; Lee, F.P.; Lin, K.C.; Lai, M.T.; Wu, C.C.; et al. Curative-Intent Aggressive Treatment Improves Survival in Elderly Patients With Locally Advanced Head and Neck Squamous Cell Carcinoma and High Comorbidity Index. Medicine (Baltimore) 2016, 95, e3268. [CrossRef]

31. Grambsch, P.M. Goodness-of-fit and diagnostics for proportional hazards regression models. Cancer Treat Res. 1995, 75, 95-112. [PubMed]

32. D'Agostino, R.B., Jr. Propensity score methods for bias reduction in the comparison of a treatment to a non-randomized control group. Stat. Med. 1998, 17, 2265-2281. [CrossRef]

33. Lau, B.; Cole, S.R.; Gange, S.J. Competing risk regression models for epidemiologic data. Am. J. Epidemiol. 2009, 170, 244-256. [CrossRef] [PubMed]

34. Austin, P.C. Balance diagnostics for comparing the distribution of baseline covariates between treatment groups in propensityscore matched samples. Stat. Med. 2009, 28, 3083-3107. [CrossRef] [PubMed]

35. Nguyen, T.L.; Collins, G.S.; Spence, J.; Daures, J.P.; Devereaux, P.J.; Landais, P.; Le Manach, Y. Double-adjustment in propensity score matching analysis: Choosing a threshold for considering residual imbalance. BMC Med. Res. Methodol. 2017, 17, 78. [CrossRef]

36. Zhang, Z.; Kim, H.J.; Lonjon, G.; Zhu, Y.; written on behalf of AME Big-Data Clinical Trial Collaborative Group. Balance diagnostics after propensity score matching. Ann. Transl. Med. 2019, 7, 16. [CrossRef]

37. Schaafsma, J.D.; Sprengers, M.E.; van Rooij, W.J.; Sluzewski, M.; Majoie, C.B.; Wermer, M.J.; Rinkel, G.J. Long-term recurrent subarachnoid hemorrhage after adequate coiling versus clipping of ruptured intracranial aneurysms. Stroke 2009, 40, 1758-1763. [CrossRef]

38. Abulhasan, Y.B.; Alabdulraheem, N.; Simoneau, G.; Angle, M.R.; Teitelbaum, J. Mortality after Spontaneous Subarachnoid Hemorrhage: Causality and Validation of a Prediction Model. World Neurosurg. 2018, 112, e799-e811. [CrossRef]

39. Vergouwen, M.D.; Jong-Tjien-Fa, A.V.; Algra, A.; Rinkel, G.J. Time trends in causes of death after aneurysmal subarachnoid hemorrhage: A hospital-based study. Neurology 2016, 86, 59-63. [CrossRef]

40. Roos, Y.B.; de Haan, R.J.; Beenen, L.F.; Groen, R.J.; Albrecht, K.W.; Vermeulen, M. Complications and outcome in patients with aneurysmal subarachnoid haemorrhage: A prospective hospital based cohort study in the Netherlands. J. Neurol. Neurosurg. Psychiatry 2000, 68, 337-341. [CrossRef]

41. Bederson, J.B.; Levy, A.L.; Ding, W.H.; Kahn, R.; DiPerna, C.A.; Jenkins, A.L., III; Vallabhajosyula, P. Acute vasoconstriction after subarachnoid hemorrhage. Neurosurgery 1998, 42, 352-360, discussion 360-352. [CrossRef] [PubMed]

42. Qureshi, A.I.; Sung, G.Y.; Suri, M.A.; Straw, R.N.; Guterman, L.R.; Hopkins, L.N. Prognostic value and determinants of ultraearly angiographic vasospasm after aneurysmal subarachnoid hemorrhage. Neurosurgery 1999, 44, 967-973, discussion 973-964. [CrossRef] [PubMed]

43. Etminan, N.; Vergouwen, M.D.; Ilodigwe, D.; Macdonald, R.L. Effect of pharmaceutical treatment on vasospasm, delayed cerebral ischemia, and clinical outcome in patients with aneurysmal subarachnoid hemorrhage: A systematic review and meta-analysis. J. Cereb. Blood Flow Metab. 2011, 31, 1443-1451. [CrossRef] [PubMed]

44. Winkler, M.K.; Dengler, N.; Hecht, N.; Hartings, J.A.; Kang, E.J.; Major, S.; Martus, P.; Vajkoczy, P.; Woitzik, J.; Dreier, J.P. Oxygen availability and spreading depolarizations provide complementary prognostic information in neuromonitoring of aneurysmal subarachnoid hemorrhage patients. J. Cereb. Blood Flow Metab. 2017, 37, 1841-1856. [CrossRef] 
45. Molyneux, A.J.; Kerr, R.S.; Birks, J.; Ramzi, N.; Yarnold, J.; Sneade, M.; Rischmiller, J.; Collaborators, I. Risk of recurrent subarachnoid haemorrhage, death, or dependence and standardised mortality ratios after clipping or coiling of an intracranial aneurysm in the International Subarachnoid Aneurysm Trial (ISAT): Long-term follow-up. Lancet Neurol. 2009, 8, 427-433. [CrossRef]

46. Investigators, C. Rates of delayed rebleeding from intracranial aneurysms are low after surgical and endovascular treatment. Stroke 2006, 37, 1437-1442. [CrossRef] [PubMed]

47. Johnston, S.C.; Dowd, C.F.; Higashida, R.T.; Lawton, M.T.; Duckwiler, G.R.; Gress, D.R.; Investigators, C. Predictors of rehemorrhage after treatment of ruptured intracranial aneurysms: The Cerebral Aneurysm Rerupture After Treatment (CARAT) study. Stroke 2008, 39, 120-125. [CrossRef]

48. Charpentier, C.; Audibert, G.; Guillemin, F.; Civit, T.; Ducrocq, X.; Bracard, S.; Hepner, H.; Picard, L.; Laxenaire, M.C. Multivariate analysis of predictors of cerebral vasospasm occurrence after aneurysmal subarachnoid hemorrhage. Stroke 1999, 30, 1402-1408. [CrossRef]

49. Badjatia, N.; Topcuoglu, M.A.; Buonanno, F.S.; Smith, E.E.; Nogueira, R.G.; Rordorf, G.A.; Carter, B.S.; Ogilvy, C.S.; Singhal, A.B. Relationship between hyperglycemia and symptomatic vasospasm after subarachnoid hemorrhage. Crit. Care Med. 2005, 33, 1603-1609, quiz 1623. [CrossRef]

50. Gross, B.A.; Rosalind Lai, P.M.; Frerichs, K.U.; Du, R. Treatment modality and vasospasm after aneurysmal subarachnoid hemorrhage. World Neurosurg. 2014, 82, e725-e730. [CrossRef]

51. Dumont, A.S.; Crowley, R.W.; Monteith, S.J.; Ilodigwe, D.; Kassell, N.F.; Mayer, S.; Ruefenacht, D.; Weidauer, S.; Pasqualin, A.; Macdonald, R.L. Endovascular treatment or neurosurgical clipping of ruptured intracranial aneurysms: Effect on angiographic vasospasm, delayed ischemic neurological deficit, cerebral infarction, and clinical outcome. Stroke 2010, 41, 2519-2524. [CrossRef]

52. Taha, M.M.; Nakahara, I.; Higashi, T.; Iwamuro, Y.; Iwaasa, M.; Watanabe, Y.; Tsunetoshi, K.; Munemitsu, T. Endovascular embolization vs surgical clipping in treatment of cerebral aneurysms: Morbidity and mortality with short-term outcome. Surg. Neurol. 2006, 66, 277-284, discussion 284. [CrossRef] [PubMed]

53. De Oliveira, J.G.; Beck, J.; Ulrich, C.; Rathert, J.; Raabe, A.; Seifert, V. Comparison between clipping and coiling on the incidence of cerebral vasospasm after aneurysmal subarachnoid hemorrhage: A systematic review and meta-analysis. Neurosurg. Rev. 2007, 30, 22-30, discussion 30-21. [CrossRef] [PubMed]

54. Xia, Z.W.; Liu, X.M.; Wang, J.Y.; Cao, H.; Chen, F.H.; Huang, J.; Li, Q.Z.; Fan, S.S.; Jiang, B.; Chen, Z.G.; et al. Coiling Is Not Superior to Clipping in Patients with High-Grade Aneurysmal Subarachnoid Hemorrhage: Systematic Review and Meta-Analysis. World Neurosurg. 2017, 98, 411-420. [CrossRef]

55. Jones, J.; Sayre, J.; Chang, R.; Tian, J.; Szeder, V.; Gonzalez, N.; Jahan, R.; Vinuela, F.; Duckwiler, G.; Tateshima, S. Cerebral vasospasm patterns following aneurysmal subarachnoid hemorrhage: An angiographic study comparing coils with clips. J. Neurointerv. Surg. 2015, 7, 803-807. [CrossRef] [PubMed]

56. Vergouwen, M.D.; Vermeulen, M.; van Gijn, J.; Rinkel, G.J.; Wijdicks, E.F.; Muizelaar, J.P.; Mendelow, A.D.; Juvela, S.; Yonas, H.; Terbrugge, K.G.; et al. Definition of delayed cerebral ischemia after aneurysmal subarachnoid hemorrhage as an outcome event in clinical trials and observational studies: Proposal of a multidisciplinary research group. Stroke 2010, 41, 2391-2395. [CrossRef] 